\title{
Symposium review: Advances in sequencing technology herald a new frontier in cattle genomics and genome-enabled selection*
}

\author{
D. M. Bickhart, ${ }^{1} \dagger \odot$ J. C. McClure, ${ }^{1}$ R. D. Schnabel, ${ }^{2,3} \odot$ B. D. Rosen, ${ }^{4}$ J. F. Medrano, ${ }^{5} \odot$ and T. P. L. Smith $^{6} \odot$ \\ ${ }^{1}$ US Dairy Forage Research Center, Agricultural Research Service, USDA, Madison, WI 53705 \\ ${ }^{2}$ Division of Animal Sciences, University of Missouri, Columbia, 65211 \\ ${ }^{3} \mathrm{MU}$ Institute for Data Science and Informatics, University of Missouri, Columbia, 65211 \\ ${ }^{4}$ Animal Genomics and Improvement Laboratory, Agricultural Research Service, USDA, Beltsville, MD 20705 \\ ${ }^{5}$ Department of Animal Science, University of California Davis, 95616 \\ ${ }^{6}$ Meat Animal Research Center, Agricultural Research Service, USDA, Clay Center, NE 68933
}

\section{ABSTRACT}

The cattle reference genome assembly has underpinned major innovations in beef and dairy genetics through genome-enabled selection, including removal of deleterious recessive variants and selection for favorable alleles affecting quantitative production traits. The initial reference assemblies, up to and including UMD3.1 and Btau4.1, were based on a combination of clone-by-clone sequencing of bacterial artificial chromosome clones generated from blood DNA of a Hereford bull and whole-genome shotgun sequencing of blood DNA from his inbred daughter/granddaughter named L1 Dominette 01449 (Dominette). The approach introduced assembly gaps, misassemblies, and errors, and it limited the ability to assemble regions that undergo rearrangement in blood cells, such as immune gene clusters. Nonetheless, the reference supported the creation of genotyping tools and provided a basis for many studies of gene expression. Recently, long-read sequencing technologies have emerged that facilitated a re-assembly of the reference genome, using lung tissue from Dominette to resolve many of the problems and providing a bridge to place historical studies in common context. The new reference, ARS-UCD1.2, successfully assembled germline immune gene clusters and improved overall continuity (i.e., reduction of gaps and inversions) by over 250-fold. This reference properly places nearly all of the legacy genetic markers used for over a decade in the industry. In this review, we discuss the improvements made to the cattle reference; remaining issues present in the assembly; tools developed to support genome-based studies in beef and dairy cattle;

Received October 1, 2019

Accepted December 3, 2019.

*Presented as part of the Joint ADSA/Interbull Session: Breeding and Genetics: Ten Years of Genomic Selection, at the ADSA Annual Meeting, Cincinnati, Ohio, June 2019.

†Corresponding author: Derek.bickhart@ars.usda.gov and the emergence of newer genome assembly methods that are producing even higher-quality assemblies for other breeds of cattle at a fraction of the cost. The new frontier for cattle genomics research will likely include a transition from the individual Hereford reference genome, to a "pan-genome" reference, representing all the DNA segments existing in commonly used cattle breeds, bringing the cattle reference into line with the current direction of human genome research.

Key words: genome assembly, SNP genotyping, reference genome

\section{TWO DECADES OF PROGRESS IN DNA SEQUENCING}

The invention of DNA sequencing by Frederick Sanger in 1977 began a new era of data generation in the field of genetics (Sanger et al., 1977). For the first time, the order of DNA bases present in an organism's genome could be determined; however, early versions of the technology were time consuming and limited to producing short sequences, relative to the size of a mammalian genome. Discrepancies in observed bases also required extensive trimming of resultant data (Ewing and Green, 1998). In addition, no dedicated tools for computational analysis of sequence data had been developed to perform assembly of overlapping short sequence reads into larger contiguous sequence (contigs). These limitations prompted rapid developments that improved the throughput, yield, and analysis of Sanger sequencing reactions (reviewed in Heather and Chain, 2016). Such improvements would prove critical to achieving the necessary scale of output for larger research projects.

The Human Genome Project (HGP) was launched in 1986 by the US Department of Energy (DeLisi, 2008), with anticipated costs exceeding US $\$ 3$ billion. Funding was included to foster the development of sequencing technologies and analysis algorithms to achieve the goal 
of a complete genome sequence. The size of mammalian genomes ( 2.5 to 3 gigabases) necessitated coordinated efforts to generate sufficient DNA sequence coverage to assemble and annotate observed portions of the genome. In the "first-generation" DNA sequencing era, genome coverage of 5- to 10-fold was considered adequate, and even this modest coverage relied on improvements to sequencing throughput by the development of the first commercial DNA sequencer (Hunkapiller et al., 1991). Eventually, a handful of major genome sequencing centers were created in the United States, each concentrating on a discrete set of human chromosomes, using a large-insert, clone-by-clone approach and employing large interdisciplinary teams of geneticists, engineers, molecular biologists, and computer scientists to address the collection and analysis of unprecedented volumes of data. A parallel private effort instead selected a whole-genome shotgun (WGS) approach, with consequent challenges of assembling the entire genome from a jumble of short reads. Eventually, both efforts created versions of the human genome from approximately 5 -fold genome coverage (International Human Genome Sequencing Consortium, 2001; Venter et al., 2001). The scope and scale of this seminal project shattered any hope that such techniques would be applied to mammalian livestock species in the near future, as noted by many prominent animal scientists at the time (Womack, 2005). However, the large expenditures of the HGP on sequencing logistics created a residual capacity for DNA sequencing that would provide an opportunity for such projects.

Large DNA sequencing centers, replete with hundreds of DNA sequencers and trained staff after the conclusion of the HGP, actively sought new projects to continue funding their operations. In a white paper published in 2002, domestic cattle were proposed as the first agricultural mammalian species to be sequenced, to develop a reference genome (Gibbs et al., 2002). Formally, the rationale for the project was the evolutionary importance of the Artiodactyla clade in comparative genomics analysis, rather than the importance of cattle as an agricultural species. In truth, the principal criteria for selection was the availability of important resources that had already been independently developed by the global community of cattle genomics researchers. These resources included genetic linkage and radiation hybrid-based genome maps (Heuertz and Hors-Cayla, 1981; Fries et al., 1993; Bishop et al., 1994; Womack et al., 1997) to guide scaffolding and detect assembly errors, a well-characterized set of large-insert clone libraries available for clone-by-clone sequencing and previously arranged into a physical map (International Bovine BAC Mapping Consortium, 2007), and a relatively large database of expressed sequence tags representing fragments of expressed transcripts from many tissues to aid in annotation of the assembly (Smith et al., 2001). In retrospect, expectations for the project were relatively muted, as the proposal had little ambition for sequencing and assembling other ruminant species. Instead, the cattle reference genome was to be a "matrix" for comparative work on other ruminant species in subsequent alignment experiments (Gibbs et al., 2002). Much of the reason for lowered expectations was due to the complexity of the underlying sequence of the cattle genome and the lack of computational tools to resolve issues in the consolidation of millions of DNA sequence reads into a consensus genome sequence (hereafter termed genome assembly).

\section{ITERATIVE PROGRESS ON THE CREATION OF THE CATTLE REFERENCE GENOME}

Many complications make reference genome assembly difficult in eutherian mammalian species. Repetitive elements comprise approximately $50 \%$ of the euchromatic genome of domestic cattle (Table 1) and have been the primary impediment in past efforts to create a continuous reference genome for the species. Although a clone-by-clone approach reduces some of these complications, it is orders of magnitude more expensive and less efficient than WGS approaches. The raw data used in the WGS approach to genome assembly consists of millions of random fragments of DNA sequence that are much smaller than the chromosome itself. Problems in genome assembly arise when a repetitive element is larger than the size of the DNA sequence read, as the terminus of the read is unable to definitively continue past the repeated element (for a review see Nagarajan and Pop, 2013). This results in fragmentation of the assembled sequence into small segments of contiguous DNA (contigs) that represent only a small fraction of the chromosome. Additionally, uneven coverage of the genome due to biases in the sampling of genomic regions from different GC\% tranches (Bentley et al., 2008) or due to amplification bias (Koren et al., 2012) can cause additional fragmentation. This problem can often be addressed via a brute-force methodology by generating additional DNA sequence coverage (frequently termed fold coverage, or simply "X coverage," based on the number of genomic equivalents) such that under-sampled regions are eventually covered by sequence reads. Finally, genomic regions of structural heterozygosity caused by segmental duplications (Bailey and Eichler, 2006), VDJ (variable, diversity, joining) recombination (Roth, 2014) when blood is used as the sequenced tissue, or other conserved structural variants (Nei and Rooney, 
Table 1. Cattle genome features estimates

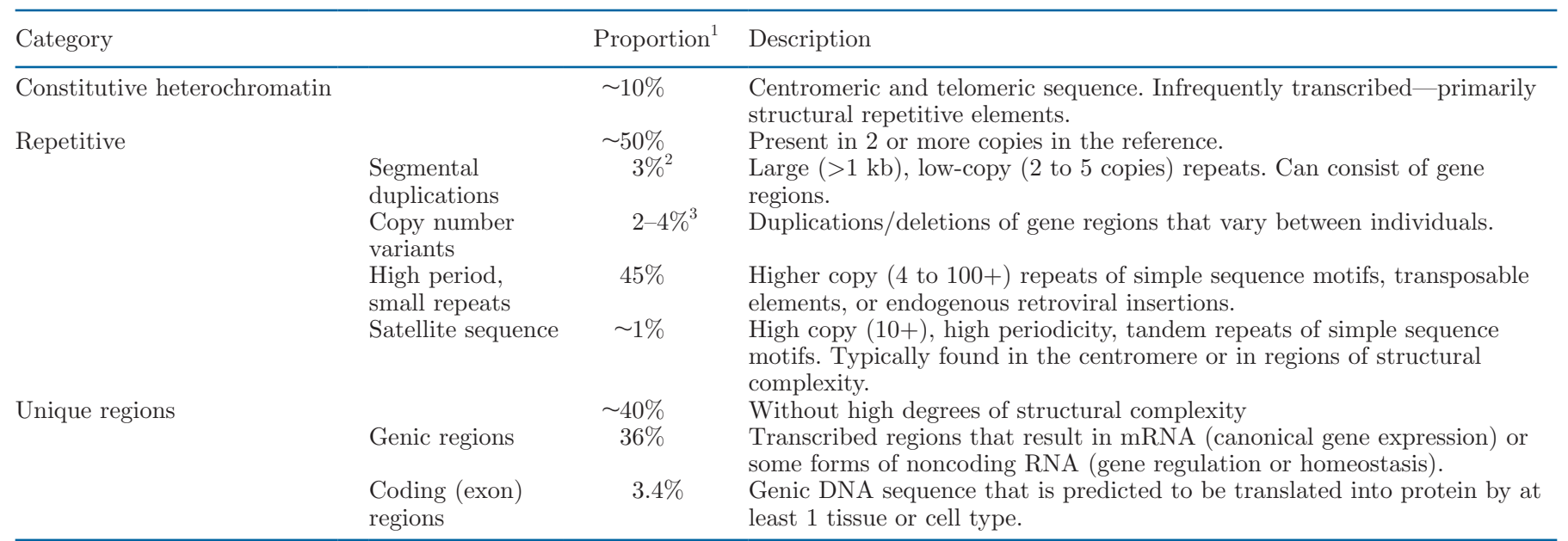

\footnotetext{
${ }^{1}$ Unless otherwise cited, these statistics are derived from the Ensembl 97 annotation of the ARS-UCD1.2 assembly (Rosen et al., 2020).

${ }^{2}$ Liu et al., 2009a.

${ }^{3}$ Hou et al., 2011; Bickhart et al., 2012.
}

2005) are intractable to assembly when sequence read lengths are shorter than the heterozygous regions. All of these factors contributed to the fragmentation of early cattle reference genome versions and necessitated the use of innovative techniques or brute-force analysis to compensate. Additional complexity is added when the 2 parental alleles of the individual sequenced are not identical, leading to confusion between allele differences and tandem repeats. To reduce complexity for future reference assembly projects, it was common to select highly inbred individuals for sequencing.

A female Hereford cow, L1 Dominette 01449, was selected as the reference animal for the cattle assembly to overcome issues related to this structural heterozygosity. The L1 Herefords were created in 1934 by USDA researchers in Miles City, Montana (Black, 1936), as an attempt to introduce line breeding to beef cattle production systems (for a review see MacNeil, 2009). A strict breeding strategy over the next 70 years resulted in a high degree of inbreeding in L1 Dominette $(30 \%$ inbreeding coefficient) and resulted in a $93 \%$ genetic relationship with her sire, L1 Domino 99375 (31\% inbreeding coefficient). This inbreeding minimized the amount of heterozygous haplotypes that would otherwise confound the incorporation of short reads into larger contigs. The DNA isolated from Dominette and Domino would be used to generate the WGS sequence reads and a bacterial artificial chromosome (BAC) library, respectively, using a strategy similar to that used in the creation of the rat reference genome (Rat Genome Sequencing Project Consortium, 2004). Initial WGS targets of Sanger reads for assembly would be $3 \times$ coverage of Dominette's genomic sequence, with a final target of $6 \times$ coverage to be achieved at a later stage of the project. Plans were made to release preliminary assemblies to the community for analysis and assay development.

The initial limitations of the cattle genome assembly did not impede its early adoption by the community at the time. Due to substantial industry interest, many genetic resources were available for cattle that would prove essential in generating a quality reference genome assembly. Many of these resources, which included microsatellite (Fries et al., 1990), genetic (Womack and Moll, 1986; Barendse et al., 1994), and radiation hybrid maps (Womack et al., 1997), were developed in the interests of improving parent verification for beef and dairy cattle breeds and for gene or QTL mapping studies. These resources were applied to early cattle reference versions to validate the sequence of DNA in assembled contigs as well as to identify the chromosomes from which they likely originated (Prasad et al., 2007).

Early releases of cattle assembly data were facilitated precisely due to this industry interest. The first public release of the Baylor Dominette reference assembly (Btau1.0) consisted of 795,212 contigs generated from $3 \times$ WGS sequence data released to NCBI's GenBank in 2004 (see Table 2). This was followed by a release of the second iteration of the assembly (Btau2.0) in 2005, which included more WGS reads ( $6 \times$ total coverage) in the assembly. The increased depth of coverage resulted in a greater than 2-fold reduction in the number of contigs, analogous to a direct increase in assembly continuity. The first polished release of the Baylor cattle assembly was the fourth iteration (Btau4.0), which used the $\mathrm{BAC}$ assembled sequence in addition to the previously 
generated WGS data set (Bovine Genome Sequencing and Analysis Consortium et al., 2009). Btau4.0 was also the first cattle reference assembly that ordered and oriented the placement of assembly contigs onto chromosome scaffolds (Liu et al., 2009b), using a previously generated composite map of genetic, radiation hybrid, and physical distances between markers (International Bovine BAC Mapping Consortium, 2007). Simultaneously, as a companion manuscript, researchers at the University of Maryland published the second iteration of their assembly of the cattle genome (UMD2) which used an alternative assembly approach (Zimin et al., 2009) as well as additional BAC-end, Sanger sequence data from the RPCI-42 BAC library (derived from a Holstein bull). Whereas the Baylor series of genome assemblies used a consensus overlap assembly algorithm (Havlak et al., 2004), the University of Maryland assemblies were generated using a graph-based approach (Zimin et al., 2009) that improved assembly continuity. These simultaneous releases did not mark the end of the Sanger sequence-based iterations of the cattle assembly. The UMD2 assembly was supplanted by the polished release of the UMD3.1 reference in 2010, which resulted in several gap closures and the placement of more contigs on chromosome scaffolds. After extensive polishing using the finished BAC sequence, the Baylor College of Medicine released the Btau4.6.1 composite assembly in 2012, including substitutions of WGS contigs with the finished BAC sequence as well as several scaffolds predicted to originate from the $\mathrm{Y}$ chromosome. In the following years, the cattle genomics community would use the Btau4.0, UMD3.1, and Btau4.6.1 assemblies extensively for basic research and practical applications.

\section{CONCURRENT IMPROVEMENTS IN GENOMIC MARKER DEVELOPMENT}

Parentage verification was an early goal for the application of the bovine reference genome to the cattle industry as a whole. The earliest form of verification was conducted through blood typing and was useful for detecting conflicts in expected parental lineage (Ferguson, 1941). This method was the gold standard for parental verification for over 50 years, until short tandem repeat loci, or microsatellites, were shown to be more effective and accurate (Fries et al., 1990; Glowatzki-Mullis et al., 1995). By the mid 2000s, cutting-edge cattle producers were beginning to use SNP, identified by comparing genome sequences from other animals to the reference genome (Heaton et al., 2002). Initially it was estimated that each SNP genotype would cost $\$ 1$ and therefore would be much more expensive than the currently accepted microsatellite technology. An initial panel of 26 highly informative SNP was released by USDA Meat Animal Research Center (MARC) scientists, for use as parentage markers. These SNP were selected from ongoing haplotype studies of 7 genes and research from the MARC bovine expressed sequence tag (EST)/SNP linkage mapping project (Heaton et al., 2002). Due to the aforementioned high costs, difficulties associated with adopting new technology, and reticence to leave established data sets and methodology behind, SNP parental verification gained traction slowly in the field over the more popular microsatellite-based analyses (Vignal et al., 2002). A useful step in getting the industry to transition from the use of microsatellites was the introduction of imputation from SNP to microsatellites. This tool allowed a smoother transition to the new technology, because it did not require genotyping of sires already tested with microsatellites (McClure et al., 2012). Even though the costs were initially higher, SNP have marked advantages over microsatellites, such as lower mutation rates (Krawczak, 1999), more streamlined laboratory methodologies, and more refined data interpretation (Kruglyak, 1997). They are also more readily standardized than microsatellites (Fries and Durstewitz, 2001), which had some legacy data inconsistencies in parental lineage identification. The advent of oligonucleotide arrays for DNA analysis in the 1990s would enable higher-throughput processing of samples by multiplexing thousands of SNP sites on a

Table 2. Cattle reference assembly iterations and features

\begin{tabular}{|c|c|c|c|c|}
\hline Assembly & $\begin{array}{l}\text { Year of } \\
\text { public release }\end{array}$ & $\begin{array}{l}\text { Contig } \\
\text { count }\end{array}$ & $\begin{array}{c}\text { Assembly } \\
\text { length (Gbp) }\end{array}$ & Features \\
\hline Btau1.0 & 2004 & 795,212 & 2.26 & Sanger sequence, $3 \times$ coverage of whole-genome shotgun (WGS) reads. \\
\hline Btau2.0 & 2005 & 321,107 & 2.64 & Additional $3 \times$ WGS read coverage $(6 \times$ total $)$. \\
\hline Btau4.0 & 2007 & 131,728 & 2.73 & Placement of Btau3.1 contigs on chromosome-representative scaffolds. \\
\hline UMD3.1 & 2010 & 77,554 & 2.67 & Use of a graph-based assembly algorithm to improve assembly continuity. \\
\hline
\end{tabular}


single assay (Pease et al., 1994). This would be a major driving technology for the development of genotyping assays in the cattle industry. By 2009, the cost of SNP genotyping had declined enough that it was less than half the cost of microsatellite genotyping (Tokarska et al., 2009). A comprehensive review comparing the effectiveness of microsatellites and SNP panels has been previously published (Fernández et al., 2013).

The initial releases of the cattle draft genome and the underlying sequence data provided the information necessary to develop more extensive SNP resources. The Affymetrix 10K cattle genotyping chip (Affy 10K) was developed by Affymetrix to provide initial parentage verification and consisted of approximately 10,000 SNP marker sites (Table 3). Developed concurrently with the release of the Btau2.0 reference assembly, the Affy $10 \mathrm{~K}$ contained SNP markers with an average spacing of $1.71 \mathrm{SNP}$ per centimorgan (Daetwyler et al., 2008). Of the markers included on this chip, $92 \%$ were identified from the WGS sequence data of 4 cattle breeds, Holstein, Angus, Limousin and Hereford), and $8 \%$ contributed by the Commonwealth Scientific and Industrial Research Organisation (CSIRO) were identified as being within genes (though not necessarily coding genes; http://tools.thermofisher.com/content/ sfs/brochures/bovine10k_snp_datasheet.pdf). Unfortunately, the draft state of the Btau2.0 reference assembly made it difficult to appropriately assign marker SNP to physical cattle chromosomes, so approximately 5,000 of the marker SNP were not assigned to chromosome linkage groups, making the utility of the chip very limited. Early experiments using this assay for QTL discovery had mixed results (Hayes et al., 2006), likely due to the larger spacing between marker sites and the lack of representation of polymorphic sites from other cattle breeds. Despite this setback, continued efforts to develop refined genotyping assays would eventually succeed, with the release of the Btau3.1 and 4.0 assemblies.

Efforts were made to identify new polymorphic SNP sites that were breed-representative and evenly spaced throughout the cattle genome. Within the span of 2 years, 2008 to 2009, several cattle genomics consortia and many participating cattle geneticists published new methods, data sets, and commercial products that would further the adoption of high-throughput genotyping in the cattle industry. The Bovine HapMap Consortium released a data set that comprised WGS sequence reads from dozens of individuals for 24 distinct breeds and 2 subspecies of cattle (Bovine HapMap Consortium, 2009). This data set improved the representation of genetic variant sites from previously unsequenced breeds and from the Bos taurus indicus subspecies. A new method for efficient sequencing of pooled samples via reduced representation library sequencing (Van Tassell et al., 2008) enabled the rapid identification of SNP for assay design. By focusing on a subset of regions in the genome, it was possible to more deeply sequence more individuals for a fixed cost, thereby increasing the breadth of population variant coverage. And finally, a method for selecting evenly spaced polymorphic marker sites for genotyping chip design (Matukumalli et al., 2009) was used to design a new cattle SNP chip: the BovineSNP50. Products resulting from these innovations were rapidly adopted not only by the cattle research community and industry but by almost all agricultural species communities, which generated a multimillion-dollar ag-genomics industry.

The success of the BovineSNP50 was slightly overshadowed by questions regarding its density of markers. There was substantial debate in the research community about whether a higher-density assay $(>100,000$ genetic markers) would greatly improve breeding value estimations (Meuwissen and Goddard, 2010) or not provide much benefit at all (VanRaden, et al., 2011) within dairy breeds of cattle. The materials to answer this question would be provided by the development of the BovineHD (referred to simply as HD) genotyping array in 2011 (Matukumalli et al., 2011). Subsequent analysis of HD genotypes from Holstein cattle showed little added value from higher-density genotypes (VanRaden et al., 2013); however, increased representation of polymorphic markers from Indicine cattle breeds

Table 3. Early SNP chips that enabled early efforts for genomic selection in cattle

\begin{tabular}{|c|c|c|c|}
\hline Genotyping chip ${ }^{1}$ & Marker count & Assembly & Contents \\
\hline Illumina SNP50 BeadChip & 54,001 & Btau3.1/4.0 & $\begin{array}{l}\text { Reduced representation library SNP }(50 \%) \text {. Bovine Hapmap }(25 \%) \text {. } \\
\text { Baylor WGS of } 4 \text { cattle breeds }(20 \%) \text {. }\end{array}$ \\
\hline Illumina BovineHD BeadChip & 777,962 & UMD3.1 & $\begin{array}{l}\text { Illumina SNP50 BeadChip ( } 7 \%) ; 180 \times \text { coverage WGS of } 20 \text { cattle } \\
\text { breeds }(93 \%) \text {. }\end{array}$ \\
\hline
\end{tabular}

\footnotetext{
${ }^{1}$ Affymetrix, Santa Clara, CA; Illumina Inc., San Diego, CA.
} 
provided improvement in genetic evaluation of these breeds (Nayee et al., 2018). Great interest also arose in generating lower-density SNP arrays that were effective for genomic selection yet could be genotyped at lower cost to the industry. Quantitative methods defined a smaller SNP set for specific breeds, resulting in lowdensity chips that were economical for population-scale genotyping (Boichard et al., 2012; Wiggans et al., 2012). Improvements in the imputation of these markers to higher-density arrays (VanRaden et al., 2013) enabled the use of these lower-density chips in routine genetic evaluations and promoted the genotyping of cows and calves. As of September 2019, the Council on Dairy Cattle Breeding reports that a total of 3,541,090 SNP genotypes have been collected from dairy cattle alone (https://queries.uscdcb.com/Genotype/cur_freq .html).

\section{REFERENCE-QUALITY ASSEMBLIES ENABLED BY LONG-READ DNA SEQUENCING}

Rapid decreases in sequencing costs and the development of longer-read sequencing technologies spurred new efforts to develop new and improved reference genome assemblies for most species. Third-generation DNA sequencers were commercially available in 2012 and enabled the creation of longer DNA sequence reads sufficient to span large repeats (Eid et al., 2009). Despite having read error rates approaching $17 \%$ false incorporation of insertions and deletions (Eid et al., 2009), longer reads were still found to be suitable for consensus overlap assembly methods (Koren et al., 2017) due to the random distribution of errors. The infancy of the technology and methods for computationally correcting its errors limited the initial use of long reads to assembling small genomes (Rasko et al., 2011) and for filling assembly gaps (Huddleston et al., 2014; Chaisson et al., 2015). However, improvements in genome assembly algorithms (Chin et al., 2013) enabled the first reference-quality assembly of a human genome using only long-read sequence data within several years of product release (Pendleton et al., 2015). Notable improvements in assembly continuity were achieved through the use of longer reads, suggesting that highquality reference genomes could be generated without numerous iterations of extensive polishing. The domestic goat, Capra hircus, was the first livestock species to be assembled primarily through long-read sequence data and achieved reference-quality continuity without extensive manual curation (Bickhart et al., 2017). The success of the goat genome project provided motivation to revisit the draft cattle genome, given the clamor by the industry for an updated reference genome and the much larger global research community for this animal.
A consortium of cattle genomics researchers determined that the most useful approach to improving the cattle reference genome would be to apply long-read sequencing to the same Hereford animal used for the original draft genome. This decision was based on the idea that existing genomics studies would be more easily integrated if the same animal or breed were used as the reference, and on the intention to minimize disruption of ongoing studies mapping the reads of other animals to the Hereford reference. Thus, lung tissue from L1 Dominette was sequenced using long-read technologies and used to create a reference assembly for cattle with minimal polishing (ARS-UCD1.2, accession number GCA_002263795.2; Rosen et al., 2020). This assembly consists of only 2,597 contigs and just 315 gaps in chromosome scaffolds (Table 2). Since the original publication of the Btau4.0 (Bovine Genome Sequencing and Analysis Consortium et al., 2009) and UMD2 references (Zimin et al., 2009), subsequent work has documented several candidate misassemblies in both versions, based on linkage (Utsunomiya et al., 2016) and recombination maps (Ma et al., 2015). The recombination map (Ma et al., 2015) was therefore used as the primary method to identify and correct errors in contigs or scaffolding. Of the many improvements resulting from the use of long-read sequencing technology in this assembly, thousands of previously unconfirmed inversions of scaffolded contigs present in the UMD3.1 reference were identified and corrected. This resulted in a $98 \%$ decrease in artifact inversion calls (Rosen et al., 2020) compared with the UMD3.1 assembly. Furthermore, the $\mathrm{X}$-chromosome pseudoautosomal region (PAR), which was noncontiguous in previous cattle reference assemblies, was resolved into a contiguous block in ARS-UCD1.2. The PAR regions are the homologous regions between the $\mathrm{X}$ and $\mathrm{Y}$ chromosomes that enable the segregation of heterologous sex chromosomes during mitosis and meiosis and are thought to be continuous regions, as reflected by the sequence in ARS-UCD1.2 (Johnson et al., 2019).

Assessment of assembly coordinates via SNP marker coordinates was essential in the diagnosis of putative misassemblies of sequence data. However, remapping of previous SNP marker probe sequences shows some discrepancies in marker placement in the new reference assembly. Using a strategy previously adopted (Koren et al., 2018), SNP marker probe sequences from the Affy 10K, BovineSNP50, and BovineHD SNP chips were aligned to the ARS-UCD1.2 reference. The proportion of discrepancies was highest in the Affy $10 \mathrm{~K}$ array (Figure 1), with 647 markers (12\% of markers with chromosome assignment) predicted to exist on a different chromosome than originally assigned. The BovineHD chip had the highest count of probe sequences 


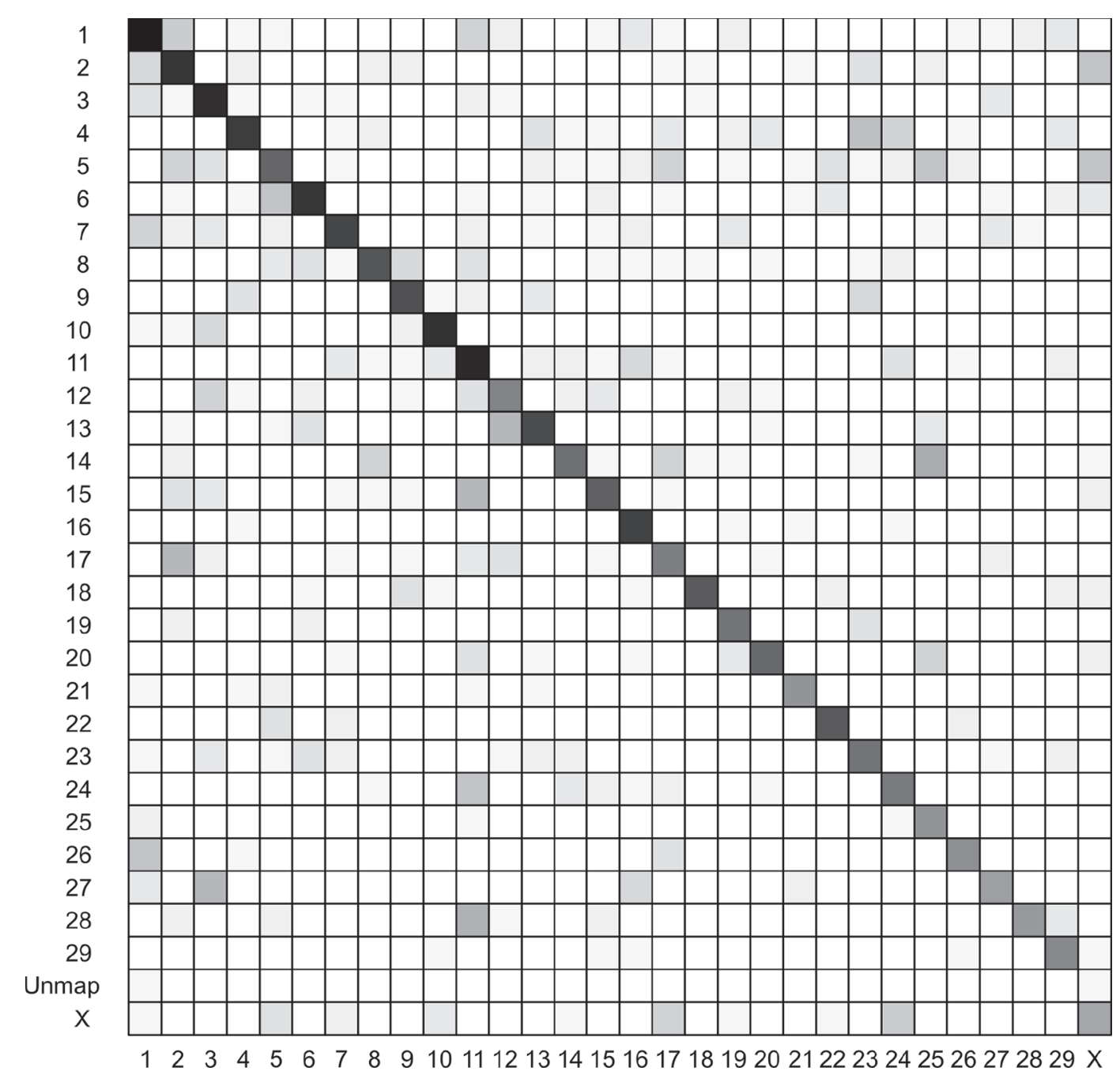

Figure 1. Network adjacency plot of predicted chromosome placement of markers on the Affymetrix (Santa Clara, CA) 10K SNP chip (xaxis) and actual marker mappings on ARS-UCD1.2 (y-axis; https://www.ncbi.nlm.nih.gov/assembly/GCF_002263795.1/). Cells are shaded darker based on the total count of markers and are not scaled.

that did not remap to ARS-UCD1.2 (1,006 out of 735,636 markers), suggesting that these markers may target genomic sequence that was not present in Dominette's genome. Out of a combined set of 794,731 SNP probe sequences from all 3 chips, 3,107 markers map to a different chromosome in ARS-UCD1.2 and 1,043 SNP probe sequences did not align to the reference sequence at all. This represents a remapping rate of $99.87 \%$, suggesting that ARS-UCD1.2 is still highly representative of legacy genotyping data in cattle. We note that all current reference genome assemblies have flaws, and several discrepancies appear to exist in ARS-UCD 1.2 that were recalcitrant to easy correction. Due to scaffolding errors, manual edits to contig order needed to be performed between scaffolds on chromosomes 7 and 10, as well as on chromosomes 21 and 27 (Rosen et al., 2020). Alignment of BovineSNP50 markers to
ARS-UCD1.2 show 11 and 18 markers for the $7-10$ and 21-27 chromosome pairs, respectively, that are still mapped on the wrong chromosomes (Figure 2). These discrepancies are most likely due to incomplete editing of the scaffolds, and represent errors to be corrected in future assembly iterations.

\section{FUTURE EXPANSIONS OF THE REFERENCE GENOME}

Structurally polymorphic haplotypes remain a major impediment to the assembly of reference genomes from diploid individuals. Previous projects achieved success by selecting the most inbred individuals for genome assembly to reduce the contrast between the 2 parental alleles present in the animal (Liu et al., 2009b) and thus decrease the possibility that the 2 alleles are sub- 
stantially different. Recently, a new method has been developed that can partition long DNA sequence reads into "bins" representing the parental haplotypes, by using k-mer signatures derived from sequence data of the parents (Koren et al., 2018). Once the reads have been sorted into bins of maternal or paternal origin, 2 genome assemblies that represent haploid genomes inherited from each parent ("haplotigs," rather than contigs) can be produced, with a concomitant increase in assembly accuracy due to the elimination of the problem of distinguishing tandem duplications from allelic variation between parental alleles. Ironically, the higher the heterozygosity of the individual sequenced, the more amenable the reads are to accurate sorting into these bins, so inbred individuals become the worst choice for this "trio binning" method. Trio binning has been applied to hybrid crosses involving cattle, such as taurine $\times$ indicine (Low et al., 2019) or cattle $\times$ yak hybrids (Rice et al., 2019). The ability to partition individual sequence reads into parental pools is partly dependent on DNA sequence read length (Koren et al., 2018), with longer reads able to compensate for lower heterozygosity between parental haplotypes. This provides hope that highly outbred wild populations could also be sequenced and assembled into reference-quality maps with limited information on the parents of the sequenced individual. Furthermore, as read length increases, interest in assembling previously uncharacterized heterochromatin regions of the genome grows. Methods that generate reads in excess of 100

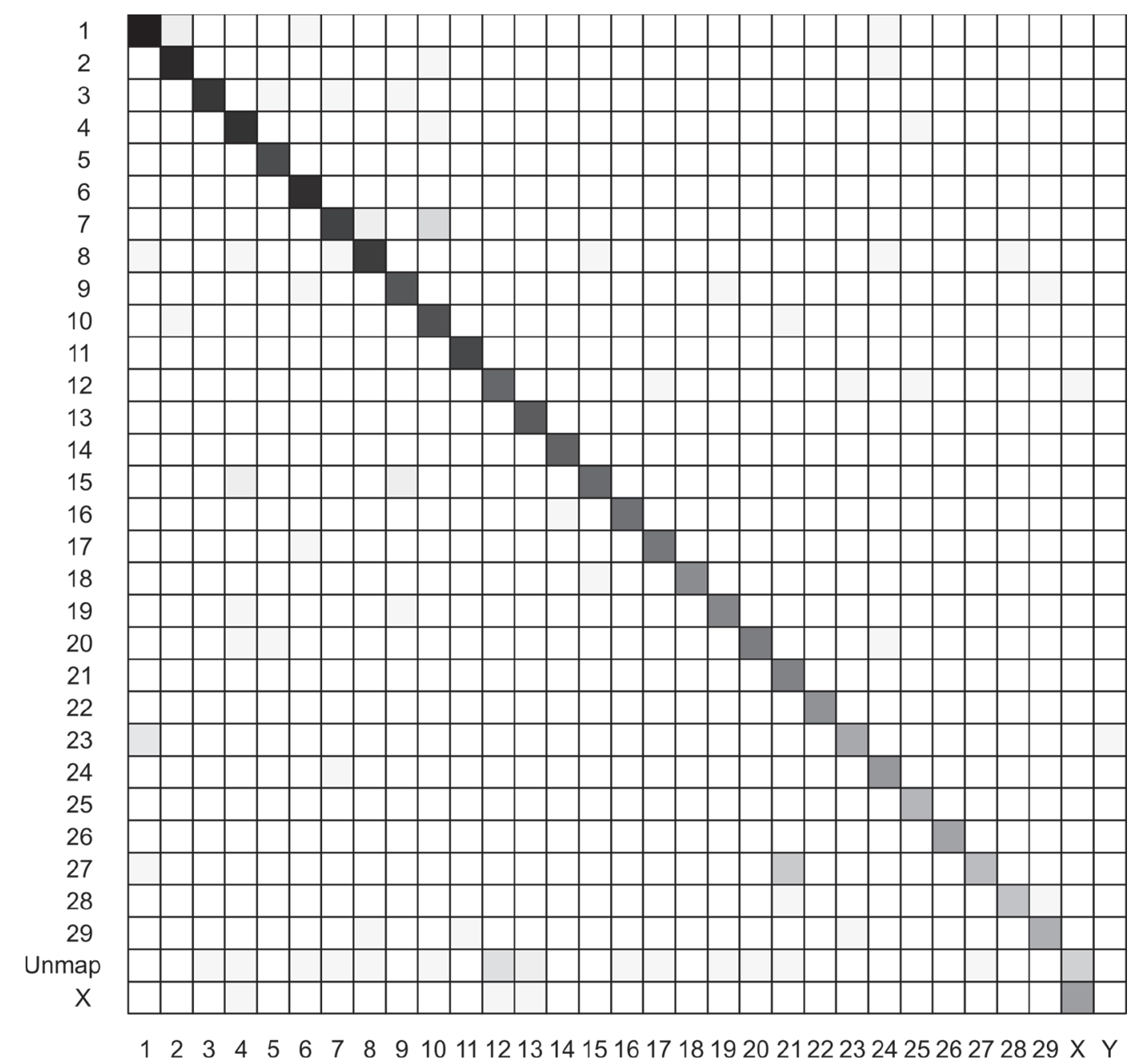

Figure 2. Network adjacency plot of predicted chromosome placement of markers on the Illumina (San Diego, CA) BovineSNP50 chip (xaxis) and actual marker mappings on ARS-UCD1.2 (y-axis; https://www.ncbi.nlm.nih.gov/assembly/GCF_002263795.1/). Cells are shaded darker based on the total count of markers and are not scaled. Major discrepancies in marker mappings between chromosomes 7 and 10 (11 markers), and 21 and 27 (18 markers) are shown as darker off-diagonal cells. These discrepancies are likely artifacts that remained after scaffold correction in ARS-UCD1.2. 
kilobases in length (termed ultra-long reads) have been used to assemble a highly continuous human genome (Miga et al., 2019), which resulted in the traversal of the centromeric region of the $\mathrm{X}$ chromosome. In contrast to a human karyotype, which consists primarily of metacentric chromosomes, cattle chromosomes are primarily acrocentric and have relatively small $\mathrm{p}$ arms. Although previous work appears to have traversed the centromere of a ruminant acrocentric chromosome (Bickhart et al., 2017), the heterochromatin structure of other ruminant chromosomes remains uncharacterized. Prevalence of diseases that are likely caused by aneuploidy (Gustavsson, 1979; Schmutz et al., 1996; Weber et al., 2007; McDaneld et al., 2012) in cattle suggests that mutations in heterochromatin (as observed in mice; Bouzinba-Segard et al., 2006) may be important indicators of disease susceptibility. In the future these mutations may be interrogated using this new technology. If the costs of generating WGS sequence data continue to decrease, this method may become a high-throughput diagnostic tool.

Further reductions in costs of DNA sequencing and improved efficiency of assembly algorithms will result in a proliferation of new assemblies for cattle and other livestock species. Whereas generation of the first cattle reference assembly required tens of millions of dollars, years of data collection, and intensive analysis (Bovine Genome Sequencing and Analysis Consortium et al., 2009), current technologies can generate equivalent resources with a small fraction of invested capital, personnel, and time. This is evidenced by the recent release of the haplotype-resolved Highland bull (Rice et al., 2019) and Angus bull assemblies (Low et al., 2019), with haplotig N50 of $71.7 \mathrm{Mbp}$ and $29.4 \mathrm{Mbp}$, respectively. These assemblies represent at least a 200-fold improvement over the continuity of the contigs of the UMD3.1 reference assembly (Zimin et al., 2009) and required minimal investment to scaffold into chromosomes. Improvements in assembly algorithms (Koren et al., 2017; Kolmogorov et al., 2019) and sequence alignment ( $\mathrm{Li}, 2016)$ have further reduced the barrier for reference assembly creation and comparative genomics, which will likely increase the frequency at which new cattle assemblies are released to the research community. Rather than succumb to the deluge of incompatible assembly drafts, new computational methods are available that enable the iterative improvement of the quality of a reference cattle sequence over time.

A dramatic change in the computational representation of reference genomes will be needed to consolidate competing assemblies and increase the representation of the reference genome. Current releases of reference genomes suffer from 2 main problems that can be sum- marized as issues with (1) iteration and (2) representation. The venerable FASTA file format (www.ncbi.nlm .nih.gov/BLAST/fasta.shtml) is still used to represent the order and orientation of DNA bases in separate scaffolds or chromosomes. With respect to iteration, changes to the sequence in the file require the creation of a new "release version" that has different coordinates than previous releases and requires realignment of all sequence data to the new file. Missing populationspecific DNA sequences represent a problem with the representation of the reference assembly and can result in unmapped, but possibly important, WGS reads. Both flaws can result in static reference genomes that underreport population-specific variation. In acknowledgment of this limitation, several groups have proposed the use of graph-based file formats (Computational Pan-Genomics Consortium, 2018; Kim et al., 2019) as an alternative representation of a reference genome. Graph formats have the benefit of being easily amended without completely disrupting sequence order and can therefore be improved by adding populationspecific variant sites or haplotypes (Computational Pan-Genomics Consortium, 2018). This can reduce the ambiguity of DNA sequence alignment for variant calling, as recently demonstrated in studies in human (Eggertsson et al., 2017) and cattle (Crysnanto et al., 2019).

The assembly of additional cattle breeds and inclusion of genetically diverse cattle populations is also likely to uncover stretches of genomic DNA that are not present in the current ARS-UCD1.2 reference, which is a problem with representation. This is to be expected, as the current Bos reference assemblies represent the DNA content of a single diploid individual - or haploid, for the recent trio method. A recent survey of African populations found megabases of DNA missing from the human reference genome (Sherman et al., 2019). Adding low-frequency or population-specific DNA sequences to a reference can greatly increase its representation; however, this will also result in a higher frequency of reported deletions of sequence in individuals that do not carry the sequence. Although graphs can represent this lower-frequency DNA sequence in populations more effectively than the FASTA format, care must be taken to properly construct the graph to avoid spurious alignment and oversaturation of potentially variant sites (Pritt et al., 2018). However, the increased accuracy for read alignment that such a pan-genome resource would provide could pave the way toward genome-enabled selection using WGS sequencing technologies in lieu of SNP genotyping arrays. Despite the benefits that assembly graphs would provide, they tend to lose the readability of the FASTA format, and they have fewer 
mature tools for data analysis - although this is rapidly changing (Kim et al., 2019).

\section{CONCLUDING REMARKS}

It has been over 10 years since the landmark publications in the journal Science that marked the beginning of the cattle reference genomics era (Bovine HapMap Consortium, 2009; Bovine Genome Sequencing and Analysis Consortium et al., 2009). As we reflect on the past, it is important to note that the development of the cattle assembly and genotyping assays pioneered the use of many techniques that would be used to uncover genetic features in other species. As predicted in the Bovine Genomic Sequencing Initiative white paper, the cattle reference genome did serve as a comparative point for future ruminant genetics (Gibbs et al., 2002). This was primarily due to the tenacity and courage of researchers in the field who continually used earlyaccess materials and improved on existing resources to generate a highly polished cattle genomics data set. The data that they collaboratively generated provides a springboard for cutting-edge methods used today.

\section{ACKNOWLEDGMENTS}

DMB and JCM were supported by appropriated project 5090-31000-024-00-D, "Determining influence of microbial, feed and animal factors on efficiency of nutrient utilization and performance in lactating dairy cows," of the Agricultural Research Service of the United States Department of Agriculture (USDA), Washington, DC. BDR was supported by appropriated project 8042-31000-001-00-D of the Agricultural Research Service of the USDA. TPLS was supported by appropriated project 3040-31000-100-00-D of the Agricultural Research Service of the USDA. The CERES cluster (part of the USDA SCINet initiative) was used in the analysis of the data presented. Mention of trade names or commercial products in this article is solely for the purpose of providing specific information and does not imply recommendation by the USDA. The USDA is an equal-opportunity provider and employer. The authors have not stated any conflicts of interest.

\section{REFERENCES}

Bailey, J. A., and E. E. Eichler. 2006. Primate segmental duplications: Crucibles of evolution, diversity and disease. Nat. Rev. Genet. 7:552-564. https://doi.org/10.1038/nrg1895.

Barendse, W., S. M. Armitage, L. M. Kossarek, A. Shalom, B. W. Kirkpatrick, A. M. Ryan, D. Clayton, L. Li, H. L. Neibergs, N. Zhang, W. M. Grosse, J. Weiss, P. Creighton, F. McCarthy, M. Ron, A. J. Teale, R. Fries, R. A. McGraw, S. S. Moore, M. Georges, M. Soller, J. E. Womack, and D. J. S. Hetzel. 1994. A genetic linkage map of the bovine genome. Nat. Genet. 6:227-235. https:/ /doi.org/10.1038/ng0394-227.

Bentley, D. R., S. Balasubramanian, H. P. Swerdlow, G. P. Smith, J. Milton, and C. G. Brown. 2008. Accurate whole human genome sequencing using reversible terminator chemistry. Nature 456:53-59. https://doi.org/10.1038/nature07517.

Bickhart, D. M., Y. Hou, S. G. Schroeder, C. Alkan, M. F. Cardone, L. K. Matukumalli, J. Song, R. D. Schnabel, M. Ventura, J. F Taylor, J. F. Garcia, C. P. Van Tassell, T. S. Sonstegard, E. E. Eichler, and G. E. Liu. 2012. Copy number variation of individual cattle genomes using next-generation sequencing. Genome Res. 22:778-790. https://doi.org/10.1101/gr.133967.111.

Bickhart, D. M., B. D. Rosen, S. Koren, B. L. Sayre, A. R. Hastie, S. Chan, J. Lee, E. T. Lam, I. Liachko, S. T. Sullivan, J. N. Burton, H. J. Huson, J. C. Nystrom, C. M. Kelley, J. L. Hutchison, Y. Zhou, J. Sun, A. Crisà, F. A. Ponce de León, J. C. Schwartz, J. A. Hammond, G. C. Waldbieser, S. G. Schroeder, G. E. Liu, M. J. Dunham, J. Shendure, T. S. Sonstegard, A. M. Phillippy, C. P. Van Tassell, and T. P. L. Smith. 2017. Single-molecule sequencing and chromatin conformation capture enable de novo reference assembly of the domestic goat genome. Nat. Genet. 49:643-650. https://doi.org/10.1038/ng.3802.

Bishop, M. D., S. M. Kappes, J. W. Keele, R. T. Stone, S. L. Sunden, G. A. Hawkins, S. S. Toldo, R. Fries, M. D. Grosz, and J. Yoo 1994. A genetic linkage map for cattle. Genetics 136:619-639.

Black, W. H. 1936. Beef and Dual Purpose Cattle Breeding. USDA, Washington, DC.

Boichard, D., H. Chung, R. Dassonneville, X. David, A. Eggen, S. Fritz, K. J. Gietzen, B. J. Hayes, C. T. Lawley, T. S. Sonstegard C. P. Van Tassell, P. M. VanRaden, K. A. Viaud-Martinez, and G. R. Wiggans. 2012. Design of a bovine low-density SNP array optimized for imputation. PLoS One 7:e34130. https://doi.org/10 .1371/journal.pone.0034130.

Bouzinba-Segard, H., A. Guais, and C. Francastel. 2006. Accumulation of small murine minor satellite transcripts leads to impaired centromeric architecture and function. Proc. Natl. Acad. Sci. USA 103:8709-8714. https://doi.org/10.1073/pnas.0508006103.

Bovine Genome Sequencing and Analysis Consortium, C. G. Elsik, R. L. Tellam, and K. C. Worley. 2009. The genome sequence of taurine cattle: A window to ruminant biology and evolution. Science 324:522-528. https://doi.org/10.1126/science.1169588.

Bovine HapMap Consortium. 2009. Genome-wide survey of SNP variation uncovers the genetic structure of cattle breeds. Science 324:528-532. https://doi.org/10.1126/science.1167936.

Chaisson, M. J. P., J. Huddleston, M. Y. Dennis, P. H. Sudmant, M. Malig, F. Hormozdiari, F. Antonacci, U. Surti, R. Sandstrom, M. Boitano, J. M. Landolin, J. A. Stamatoyannopoulos, M. W. Hunkapiller, J. Korlach, and E. E. Eichler. 2015. Resolving the complexity of the human genome using single-molecule sequencing. Nature 517:608-611. https://doi.org/10.1038/nature13907.

Chin, C.-S., D. H. Alexander, P. Marks, A. A. Klammer, J. Drake, C. Heiner, A. Clum, A. Copeland, J. Huddleston, E. E. Eichler, S. W. Turner, and J. Korlach. 2013. Nonhybrid, finished microbial genome assemblies from long-read SMRT sequencing data. Nat. Methods 10:563-569. https://doi.org/10.1038/nmeth.2474.

Computational Pan-Genomics Consortium. 2018. Computational pan-genomics: Status, promises and challenges. Brief. Bioinform. 19:118-135. https://doi.org/10.1093/bib/bbw089.

Crysnanto, D., C. Wurmser, and H. Pausch. 2019. Accurate sequence variant genotyping in cattle using variation-aware genome graphs. Genet. Sel. Evol. 51:21. https://doi.org/10.1186/s12711-019-0462 -x.

Daetwyler, H. D., F. S. Schenkel, M. Sargolzaei, and J. A. B. Robinson. 2008. A genome scan to detect quantitative trait loci for economically important traits in Holstein cattle using two methods and a dense single nucleotide polymorphism map. J. Dairy Sci. 91:3225-3236. https://doi.org/10.3168/jds.2007-0333.

DeLisi, C. 2008. Meetings that changed the world: Santa Fe 1986: Human genome baby-steps. Nature 455:876-877. https://doi.org/10 $.1038 / 455876 \mathrm{a}$ 
Eggertsson, H. P., H. Jonsson, S. Kristmundsdottir, E. Hjartarson, B. Kehr, G. Masson, F. Zink, K. E. Hjorleifsson, A. Jonasdottir, A. Jonasdottir, I. Jonsdottir, D. F. Gudbjartsson, P. Melsted, K. Stefansson, and B. V. Halldorsson. 2017. Graphtyper enables population-scale genotyping using pangenome graphs. Nat. Genet. 49:1654-1660. https://doi.org/10.1038/ng.3964.

Eid, J., A. Fehr, J. Gray, K. Luong, J. Lyle, G. Otto, P. Peluso, D. Rank, P. Baybayan, B. Bettman, A. Bibillo, K. Bjornson, B. Chaudhuri, F. Christians, R. Cicero, S. Clark, R. Dalal, A. Dewinter, J. Dixon, M. Foquet, A. Gaertner, P. Hardenbol, C. Heiner, K. Hester, D. Holden, G. Kearns, X. Kong, R. Kuse, Y. Lacroix, S. Lin, P. Lundquist, C. Ma, P. Marks, M. Maxham, D. Murphy, I. Park, T. Pham, M. Phillips, J. Roy, R. Sebra, G. Shen, J. Sorenson, A. Tomaney, K. Travers, M. Trulson, J. Vieceli, J. Wegener, D. Wu, A. Yang, D. Zaccarin, P. Zhao, F. Zhong, J. Korlach, and S. Turner. 2009. Real-time DNA sequencing from single polymerase molecules. Science 323:133-138. https://doi.org/10.1126/ science. 1162986

Ewing, B., and P. Green. 1998. Base-calling of automated sequencer traces using phred. II. Error probabilities. Genome Res. 8:186-194. https://doi.org/10.1101/gr.8.3.186.

Ferguson, L. 1941. Heritable antigens in the erythrocytes of cattle. J. Immunol. 40:213-242.

Fernández, M. E., D. E. Goszczynski, J. P. Lirón, E. E. Villegas-Castagnasso, M. H. Carino, M. V. Ripoli, A. Rogberg-Muñoz, D. M. Posik, P. Peral-García, and G. Giovambattista. 2013. Comparison of the effectiveness of microsatellites and SNP panels for genetic identification, traceability and assessment of parentage in an inbred Angus herd. Genet. Mol. Biol. 36:185-191. https://doi.org/10 $.1590 /$ S1415-47572013000200008.

Fries, R., and G. Durstewitz. 2001. Digital DNA signatures for animal tagging. Nat. Biotechnol. 19:508. https://doi.org/10.1038/89213.

Fries, R., A. Eggen, and G. Stranzinger. 1990. The bovine genome contains polymorphic microsatellites. Genomics 8:403-406. https:/ /doi.org/10.1016/0888-7543(90)90301-A.

Fries, R., A. Eggen, and J. E. Womack. 1993. The bovine genome map. Mamm. Genome 4:405-428. https://doi.org/10.1007/BF00296815.

Gibbs, R., G. Weinstock, S. Kappes, L. Schook, L. Skow, and J. Womack. 2002. Bovine Genomic Sequencing Initiative: Cattle-izing the human genome. Accessed Jan. 17, 2020. https://www.genome.gov/ Pages/Research/Sequencing/SeqProposals/BovineSEQ.pdf.

Glowatzki-Mullis, M. L., C. Gaillard, G. Wigger, and R. Fries. 1995. Microsatellite-based parentage control in cattle. Anim. Genet. 26:7-12. https://doi.org/10.1111/j.1365-2052.1995.tb02612.x.

Gustavsson, I. 1979. Distribution and effects of the 1/29 Robertsonian translocation in cattle. J. Dairy Sci. 62:825-835. https://doi.org/ 10.3168/jds.S0022-0302(79)83334-2.

Havlak, P., R. Chen, K. J. Durbin, A. Egan, Y. Ren, X.-Z. Song, G. M. Weinstock, and R. A. Gibbs. 2004. The Atlas genome assembly system. Genome Res. 14:721-732. https://doi.org/10.1101/gr .2264004

Hayes, B. J., A. J. Chamberlain, and M. E. Goddard. 2006. Use of markers in linkage disequilibrium with QTL in breeding programs. Proc. 8th World Congr. Genet. Appl. Livest. Prod. Belo Horizonte, Minas Gerais, Brazil. Instituto Prociência, Minas Gerais, Brazil.

Heather, J. M., and B. Chain. 2016. The sequence of sequencers: The history of sequencing DNA. Genomics 107:1-8. https://doi.org/10 .1016/j.ygeno.2015.11.003.

Heaton, M. P., G. P. Harhay, G. L. Bennett, R. T. Stone, W. M. Grosse, E. Casas, J. W. Keele, T. P. L. Smith, C. G. ChitkoMcKown, and W. W. Laegreid. 2002. Selection and use of SNP markers for animal identification and paternity analysis in U.S. beef cattle. Mamm. Genome 13:272-281. https://doi.org/10.1007/ s00335-001-2146-3.

Heuertz, S., and M.-C. Hors-Cayla. 1981. Cattle gene mapping by somatic cell hybridization study of 17 enzyme markers. Cytogenet. Cell Genet. 30:137-145. https://doi.org/10.1159/000131601.

Hou, Y., G. E. Liu, D. M. Bickhart, M. F. Cardone, K. Wang, E. Kim, L. K. Matukumalli, M. Ventura, J. Song, P. M. VanRaden, T. S. Sonstegard, and C. P. Van Tassell. 2011. Genomic characteristics of cattle copy number variations. BMC Genomics 12:127. https:// doi.org/10.1186/1471-2164-12-127.

Huddleston, J., S. Ranade, M. Malig, F. Antonacci, M. Chaisson, L. Hon, P.H. Sudmant, T.A. Graves, C. Alkan, M.Y. Dennis, R.K. Wilson, S.W. Turner, J. Korlach, and E.E. Eichler. 2014. Reconstructing complex regions of genomes using long-read sequencing technology. Genome Res. 24:688-696. https://doi.org/10.1101/gr .168450 .113

Hunkapiller, T., R. J. Kaiser, B. F. Koop, and L. Hood. 1991. Largescale and automated DNA sequence determination. Science 254:59-67. https://doi.org/10.1126/science.1925562.

International Bovine BAC Mapping Consortium. 2007. A physical map of the bovine genome. Genome Biol. 8:R165. https://doi.org/ 10.1186/gb-2007-8-8-r165.

International Human Genome Sequencing Consortium. 2001. Initial sequencing and analysis of the human genome. Nature 409:860921. https://doi.org/10.1038/35057062.

Johnson, T., M. Keehan, C. Harland, T. Lopdell, R. J. Spelman, S. R. Davis, B. D. Rosen, T. P. L. Smith, and C. Couldrey. 2019. Short communication: Identification of the pseudoautosomal region in the Hereford bovine reference genome assembly ARS-UCD1.2. J. Dairy Sci. 102:3254-3258. https://doi.org/10.3168/jds.2018-15638.

Kim, D., J. M. Paggi, C. Park, C. Bennett, and S. L. Salzberg. 2019 Graph-based genome alignment and genotyping with HISAT2 and HISAT-genotype. Nat. Biotechnol. 37:907-915. https://doi.org/10 .1038/s41587-019-0201-4.

Kolmogorov, M., J. Yuan, Y. Lin, and P. A. Pevzner. 2019. Assembly of long, error-prone reads using repeat graphs. Nat. Biotechnol. 37:540-546. https://doi.org/10.1038/s41587-019-0072-8.

Koren, S., A. Rhie, B. P. Walenz, A. T. Dilthey, D. M. Bickhart, S. B. Kingan, S. Hiendleder, J. L. Williams, T. P. L. Smith, and A. M. Phillippy. 2018. De novo assembly of haplotype-resolved genomes with trio binning. Nat. Biotechnol. 36:1174-1182. https://doi.org/ $10.1038 /$ nbt.4277.

Koren, S., M. C. Schatz, B. P. Walenz, J. Martin, J. T. Howard, G. Ganapathy, Z. Wang, D. A. Rasko, W. R. McCombie, E. D. Jarvis, and A. M. Phillippy. 2012. Hybrid error correction and de novo assembly of single-molecule sequencing reads. Nat. Biotechnol. 30:693-700. https://doi.org/10.1038/nbt.2280.

Koren, S., B. P. Walenz, K. Berlin, J. R. Miller, N. H. Bergman, and A. M. Phillippy. 2017. Canu: Scalable and accurate long-read assembly via adaptive k-mer weighting and repeat separation. Genome Res. 27:722-736. https://doi.org/10.1101/071282.

Krawczak, M. 1999. Informativity assessment for biallelic single nucleotide polymorphisms. Electrophoresis 20:1676-1681. https:/ /doi.org/10.1002/(SICI)1522-2683(19990101)20:8<1676::AIDELPS1676>3.0.CO;2-D

Kruglyak, L. 1997. The use of a genetic map of biallelic markers in linkage studies. Nat. Genet. 17:21-24. https://doi.org/10.1038/ ng0997-21.

Li, H. 2016. Minimap and miniasm: Fast mapping and de novo assembly for noisy long sequences. Bioinformatics 32:2103-2110. https:/ /doi.org/10.1093/bioinformatics/btw152.

Liu, G. E., M. Ventura, A. Cellamare, L. Chen, Z. Cheng, B. Zhu, C. Li, J. Song, and E. E. Eichler. 2009a. Analysis of recent segmental duplications in the bovine genome. BMC Genomics 10:571. https: //doi.org/10.1186/1471-2164-10-571.

Liu, Y., X. Qin, X.-Z. H. Song, H. Jiang, Y. Shen, K. J. Durbin, S. Lien, M. P. Kent, M. Sodeland, Y. Ren, L. Zhang, E. Sodergren, P. Havlak, K. C. Worley, G. M. Weinstock, and R. A. Gibbs. 2009b. Bos taurus genome assembly. BMC Genomics 10:180. https://doi .org/10.1186/1471-2164-10-180.

Low, W. Y., R. Tearle, R. Liu, S. Koren, A. Rhie, D. M. Bickhart, B. D. Rosen, Z. N. Kronenberg, S. B. Kingan, E. Tseng, F. ThibaudNissen, F. J. Martin, K. Billis, J. Ghurye, A. R. Hastie, J. Lee, A. W. C. Pang, M. P. Heaton, A. M. Phillippy, S. Hiendleder, T. P. L. Smith, and J. L. Williams. 2019. Haplotype-resolved cattle genomes provide insights into structural variation and adaptation. bioRxiv 720797. https://doi.org/10.1101/720797.

Ma, L., J. R. O'Connell, P. M. VanRaden, B. Shen, A. Padhi, C. Sun, D. M. Bickhart, J. B. Cole, D. J. Null, G. E. Liu, Y. Da, and G. 
R. Wiggans. 2015. Cattle sex-specific recombination and genetic control from a large pedigree analysis. PLoS Genet. 11:e1005387. https://doi.org/10.1371/journal.pgen.1005387.

MacNeil, M. D. 2009. Invited review: Research contributions from seventy-five years of breeding Line 1 Hereford cattle at Miles City, Montana. J. Anim. Sci. 87:2489-2501. https://doi.org/10.2527/jas .2009-1909.

Matukumalli, L., S. Schroeder, S. DeNise, T. Sonstegard, C. Lawley, M. Georges, W. Coppieters, K. Gietzen, J. Medrano, G. Rincon, and Associates. 2011. Analyzing LD blocks and CNV segments in cattle: Novel genomic features identified using the BovineHD BeadChip. Illumina Inc., San Diego, CA.

Matukumalli, L. K., C. T. Lawley, R. D. Schnabel, J. F. Taylor, M. F. Allan, M. P. Heaton, J. O'Connell, S. S. Moore, T. P. L. Smith, T. S. Sonstegard, and C. P. Van Tassell. 2009. Development and characterization of a high density SNP genotyping assay for cattle. PLoS One 4:e5350. https://doi.org/10.1371/journal.pone.0005350.

McClure, M., T. Sonstegard, G. Wiggans, and C. P. Van Tassell. 2012. Imputation of microsatellite alleles from dense SNP genotypes for parental verification. Front. Genet. 3. https://doi.org/10.3389/ fgene.2012.00140

McDaneld, T. G., L. A. Kuehn, M. G. Thomas, W. M. Snelling, T. S. Sonstegard, L. K. Matukumalli, T. P. L. Smith, E. J. Pollak, and J. W. Keele. 2012. Y are you not pregnant: Identification of Y chromosome segments in female cattle with decreased reproductive efficiency. J. Anim. Sci. 90:2142-2151. https://doi.org/10.2527/jas 2011-4536.

Meuwissen, T., and M. Goddard. 2010. Accurate prediction of genetic values for complex traits by whole-genome resequencing. Genetics 185:623-631. https://doi.org/10.1534/genetics.110.116590.

Miga, K. H., S. Koren, A. Rhie, M. R. Vollger, A. Gershman, A. Bzikadze, S. Brooks, E. Howe, D. Porubsky, G. A. Logsdon, V. A. Schneider, T. Potapova, J. Wood, W. Chow, J. Armstrong, J. Fredrickson, E. Pak, K. Tigyi, M. Kremitzki, C. Markovic, V. Maduro, A. Dutra, G. G. Bouffard, A. M. Chang, N. F. Hansen, F. Thibaud-Nissen, A. D. Schmitt, J.-M. Belton, S. Selvaraj, M. Y. Dennis, D. C. Soto, R. Sahasrabudhe, G. Kaya, J. Quick, N. J. Loman, N. Holmes, M. Loose, U. Surti, R. A. Risques, T. A. G. Lindsay, R. Fulton, I. Hall, B. Paten, K. Howe, W. Timp, A. Young, J. C. Mullikin, P. A. Pevzner, B. A. Sullivan, E. A. Eichler, and A. M. Phillippy. 2019. Telomere-to-telomere assembly of a complete human X chromosome. bioRxiv 735928. https://doi.org/ $10.1101 / 735928$

Nagarajan, N., and M. Pop. 2013. Sequence assembly demystified. Nat. Rev. Genet. 14:157-167. https://doi.org/10.1038/nrg3367.

Nayee, N., G. Sahana, S. Gajjar, A. Sudhakar, K. Trivedi, M. S. Lund, and B. Guldbrandtsen. 2018. Suitability of existing commercial single nucleotide polymorphism chips for genomic studies in Bos indicus cattle breeds and their Bos taurus crosses. J. Anim. Breed. Genet. 135:432-441. https://doi.org/10.1111/jbg.12356.

Nei, M., and A. P. Rooney. 2005. Concerted and birth-and-death evolution of multigene families. Annu. Rev. Genet. 39:121-152. https: //doi.org/10.1146/annurev.genet.39.073003.112240.

Pease, A. C., D. Solas, E. J. Sullivan, M. T. Cronin, C. P. Holmes, and S. P. Fodor. 1994. Light-generated oligonucleotide arrays for rapid DNA sequence analysis. Proc. Natl. Acad. Sci. USA 91:5022-5026. https://doi.org/10.1073/pnas.91.11.5022.

Pendleton, M., R. Sebra, A. W. C. Pang, A. Ummat, O. Franzen, T. Rausch, A. M. Stütz, W. Stedman, T. Anantharaman, A. Hastie, H. Dai, M. H.-Y. Fritz, H. Cao, A. Cohain, G. Deikus, R. E. Durrett, S. C. Blanchard, R. Altman, C.-S. Chin, Y. Guo, E. E. Paxinos, J. O. Korbel, R. B. Darnell, W. R. McCombie, P.-Y. Kwok, C. E. Mason, E. E. Schadt, and A. Bashir. 2015. Assembly and diploid architecture of an individual human genome via singlemolecule technologies. Nat. Methods 12:780-786. https://doi.org/ 10.1038/nmeth.3454.

Prasad, A., T. Schiex, S. McKay, B. Murdoch, Z. Wang, J. E. Womack, P. Stothard, and S. S. Moore. 2007. High resolution radiation hybrid maps of bovine chromosomes 19 and 29: Comparison with the bovine genome sequence assembly. BMC Genomics 8:310. https://doi.org/10.1186/1471-2164-8-310.
Pritt, J., N.-C. Chen, and B. Langmead. 2018. FORGe: Prioritizing variants for graph genomes. Genome Biol. 19:220. https://doi.org/ 10.1186/s13059-018-1595-x.

Rasko, D. A., D. R. Webster, J. W. Sahl, A. Bashir, N. Boisen, F. Scheutz, E. E. Paxinos, R. Sebra, C.-S. Chin, D. Iliopoulos, A. Klammer, P. Peluso, L. Lee, A. O. Kislyuk, J. Bullard, A. Kasarskis, S. Wang, J. Eid, D. Rank, J. C. Redman, S. R. Steyert, J. Frimodt-Møller, C. Struve, A. M. Petersen, K. A. Krogfelt, J. P. Nataro, E. E. Schadt, and M. K. Waldor. 2011. Origins of the $E$. coli strain causing an outbreak of hemolytic-uremic syndrome in Germany. N. Engl. J. Med. 365:709-717. https://doi.org/10.1056/ NEJMoa1106920.

Rat Genome Sequencing Project Consortium. 2004. Genome sequence of the Brown Norway rat yields insights into mammalian evolution. Nature 428:493-521. https://doi.org/10.1038/nature02426.

Rice, E. S., S. Koren, A. Rhie, M. P. Heaton, T. S. Kalbfleisch, T. Hardy, P. H. Hackett, D. M. Bickhart, B. D. Rosen, B. V. Ley, N W. Maurer, R. E. Green, A. M. Phillippy, J. L. Petersen, and T. P. L. Smith. 2019. Chromosome-length haplotigs for yak and cattle from trio binning assembly of an F1 hybrid. bioRxiv 737171. https: //doi.org/10.1101/737171

Rosen, B. D., D. M. Bickhart, R. D. Schnabel, S. Koren, C. G. Elsik, E. Tseng, T. N. Rowan, W. Y. Low, A. Zimin, C. Couldrey, R. Hall, W. Li, A. Rhie, J. Ghurye, S. D. McKay, F. Thibaud-Nissen, J. Hoffman, B. M Murdoch, W. M. Snelling, T. G. McDaneld, J. A. Hammond, J. C. Schwartz, W. Nandolo, D. E. Hagen, C. Dreischer, S. J. Schultheiss, S. G. Schroeder, A. M. Phillippy, J. B. Cole, C. P. Van Tassell, G. Liu, T. P. L. Smith, and J. F. Medrano. 2020. De novo assembly of the cattle reference genome with single-molecule sequencing. GigaScience 9:giaa021. https:// doi.org/10.1093/gigascience/giaa021.

Roth, D. B. 2014. V(D)J Recombination: Mechanism, errors, and fidelity. Microbiol. Spectr. 2. https://doi.org/10.1128/microbiolspec .MDNA3-0041-2014.

Sanger, F., S. Nicklen, and A. R. Coulson. 1977. DNA sequencing with chain-terminating inhibitors. Proc. Natl. Acad. Sci. USA 74:54635467. https://doi.org/10.1073/pnas.74.12.5463.

Schmutz, S. M., J. S. Moker, E. G. Clark, and J. P. Orr. 1996. Chromosomal aneuploidy associated with spontaneous abortions and neonatal losses in cattle. J. Vet. Diagn. Invest. 8:91-95. https:// doi.org/10.1177/104063879600800114.

Sherman, R. M., J. Forman, V. Antonescu, D. Puiu, M. Daya, N. Rafaels, M. P. Boorgula, S. Chavan, C. Vergara, V. E. Ortega, A. M. Levin, C. Eng, M. Yazdanbakhsh, J. G. Wilson, J. Marrugo, L. A. Lange, L. K. Williams, H. Watson, L. B. Ware, C. O. Olopade, O. Olopade, R. R. Oliveira, C. Ober, D. L. Nicolae, D. A. Meyers, A. Mayorga, J. Knight-Madden, T. Hartert, N. N. Hansel, M. G. Foreman, J. G. Ford, M. U. Faruque, G. M. Dunston, L. Caraballo, E. G. Burchard, E. R. Bleecker, M. I. Araujo, E. F. Herrera-Paz, M. Campbell, C. Foster, M. A. Taub, T. H. Beaty, I. Ruczinski, R. A. Mathias, K. C. Barnes, and S. L. Salzberg. 2019. Assembly of a pan-genome from deep sequencing of 910 humans of African descent. Nat. Genet. 51:30-35. https://doi.org/10.1038/ s41588-018-0273-y.

Smith, T. P. L., W. M. Grosse, B. A. Freking, A. J. Roberts, R. T. Stone, E. Casas, J. E. Wray, J. White, J. Cho, S. C. Fahrenkrug, G. L. Bennett, M. P. Heaton, W. W. Laegreid, G. A. Rohrer, C. G. Chitko-McKown, G. Pertea, I. Holt, S. Karamycheva, F. Liang, J. Quackenbush, and J. W. Keele. 2001. Sequence evaluation of four pooled-tissue normalized bovine cDNA libraries and construction of a gene index for cattle. Genome Res. 11:626-630. https://doi .org/10.1101/gr.170101.

Tokarska, M., T. Marshall, R. Kowalczyk, J. M. Wójcik, C. Pertoldi, T. N. Kristensen, V. Loeschcke, V. R. Gregersen, and C. Bendixen. 2009. Effectiveness of microsatellite and SNP markers for parentage and identity analysis in species with low genetic diversity: The case of European bison. Heredity 103:326-332. https://doi.org/10 .1038/hdy.2009.73.

Utsunomiya, A. T. H., D. J. A. Santos, S. A. Boison, Y. T. Utsunomiya, M. Milanesi, D. M. Bickhart, P. Ajmone-Marsan, J. Sölkner, J. F. Garcia, R. da Fonseca, and M. V. G. B. da Silva. 2016. 
Revealing misassembled segments in the bovine reference genome by high resolution linkage disequilibrium scan. BMC Genomics 17:705. https://doi.org/10.1186/s12864-016-3049-8.

Van Tassell, C. P., T. P. L. Smith, L. K. Matukumalli, J. F. Taylor, R. D. Schnabel, C. T. Lawley, C. D. Haudenschild, S. S. Moore, W. C. Warren, and T. S. Sonstegard. 2008. SNP discovery and allele frequency estimation by deep sequencing of reduced representation libraries. Nat. Methods 5:247-252. https://doi.org/10.1038/ nmeth.1185.

VanRaden, P. M., D. J. Null, M. Sargolzaei, G. R. Wiggans, M. E. Tooker, J. B. Cole, T. S. Sonstegard, E. E. Connor, M. Winters, J. B. C. H. M. van Kaam, A. Valentini, B. J. Van Doormaal, M. A. Faust, and G. A. Doak. 2013. Genomic imputation and evaluation using high-density Holstein genotypes. J. Dairy Sci. 96:668-678. https://doi.org/10.3168/jds.2012-5702.

VanRaden, P. M., J. R. O'Connell, G. R. Wiggans, and K. A. Weigel. 2011. Genomic evaluations with many more genotypes. Genet. Sel. Evol. 43:10. https://doi.org/10.1186/1297-9686-43-10.

Venter, J. C., M. D. Adams, E. W. Myers, P. W. Li, R. J. Mural, and G. G. Sutton. 2001. The sequence of the human genome. Science 291:1304-1351. https://doi.org/10.1126/science.1058040.

Vignal, A., D. Milan, M. SanCristobal, and A. Eggen. 2002. A review on SNP and other types of molecular markers and their use in animal genetics. Genet. Sel. Evol. 34:275-305. https://doi.org/10 $.1186 / 1297-9686-34-3-275$

Weber, A. F., J. Waddell, M. L. Fahning, L. C. Buoen, and B. E. Seguin. 2007. Cytologic and ultrastructural evidence of spermatid selection in a $1 / 29,14 / 20$ centric fusion bull. Can. Vet. J. 48:1255-1257.
Wiggans, G. R., T. A. Cooper, P. M. VanRaden, K. M. Olson, and M. E. Tooker. 2012. Use of the Illumina Bovine3K BeadChip in dairy genomic evaluation. J. Dairy Sci. 95:1552-1558. https://doi.org/ $10.3168 /$ jds.2011-4985.

Womack, J. E. 2005. Advances in livestock genomics: Opening the barn door. Genome Res. 15:1699-1705. https://doi.org/10.1101/ gr.3809105.

Womack, J. E., J. S. Johnson, E. K. Owens, C. E. Rexroad, J. Schläpfer, and Y.-P. Yang. 1997. A whole-genome radiation hybrid panel for bovine gene mapping. Mamm. Genome 8:854-856. https://doi .org/10.1007/s003359900593.

Womack, J. E., and Y. D. Moll. 1986. Gene map of the cow: Conservation of linkage with mouse and man. J. Hered. 77:2-7. https://doi .org/10.1093/oxfordjournals.jhered.a110160.

Zimin, A. V., A. L. Delcher, L. Florea, D. R. Kelley, M. C. Schatz, D. Puiu, F. Hanrahan, G. Pertea, C. P. Van Tassell, T. S. Sonstegard, G. Marçais, M. Roberts, P. Subramanian, J. A. Yorke, and S. L. Salzberg. 2009. A whole-genome assembly of the domestic cow, Bos taurus. Genome Biol. 10:R42. https://doi.org/10.1186/ gb-2009-10-4-r42.

\section{ORCIDS}

D. M. Bickhart @ https://orcid.org/0000-0003-2223-9285

R. D. Schnabel ๑ https://orcid.org/0000-0001-5018-7641

J. F. Medrano 으 https://orcid.org/0000-0001-7113-3183

T. P. L. Smith ๑ https://orcid.org/0000-0003-1611-6828 